\title{
PAUPERIZAÇÃO, CONSUMISMO, SUPERSTIÇÕES E PEDAGOGIA SOCIAL
}

\author{
PAUPERIZATION, CONSUMERISM, SUPERSTITIONS \\ AND SOCIAL PEDAGOGY
}

José B. Duarte

Universidade Lusófona de Humanidades e Tecnologias - ULHT.

Lisboa- Portugal.

j.b.duarte@netcabo.pt

\begin{abstract}
Resumo: Este ensaio procura responder a uma questão tripartida: Como pode a pedagogia social reagir face 1) ao crescente "precariado" ou pauperização que ameaça os trabalhadores de todo o mundo, 2) à alienação consumista promovida pela poderosa publicidade assegurada pelo capitalismo internacional, 3) a outras formas de alienação como a pseudociência e as múltiplas superstições, fenómenos espalhados por todo o mundo, sob diferentes formas? Com base em diferentes autores (entre eles Standing, Marcuse, Bauman, Sagan e Popper) argumentamos que à escola, à comunicação social e às organizações sociais, ligadas a autarquias ou a associações populares, compete promover uma reflexão fundamental quanto à ameaça de pauperização que paira sobre a humanidade e quanto à atmosfera do consumismo promovida pelas forças do mercado globalizado. Mas é imperativo também que essas mesmas agências de pedagogia social promovam o debate sobre a pseudociência e as múltiplas formas de superstição, de modo a desenvolver na sociedade atual a consciência crítica face a todas as formas de alienação e o acesso a uma visão de base científica sobre a história da humanidade e do universo.
\end{abstract}

Palavras-chave: Alienação. Educação científica. Pseudociência. Superstições.

Abstract: This essay seeks to answer a threefold question: How can the social pedagogy react to 1) the growing "precariat" or pauperization threatening the workers of all the world, 2) to the consumerist alienation promoted by the powerful publicity paid by international capitalism, 3) to other forms of alienation such as pseudoscience and multiple superstitions, phenomena scattered all over the world in different forms? Supported by different writers (Standing, Marcuse, Bauman, Sagan, Popper) we propose that the school, the media and social organizations (linked to local official organizations or associations) should promote a fundamental reflection on the pauperization threatening mankind and on the atmosphere of consumerism promoted by the forces of the globalized market. But it is imperative these same agencies of social pedagogy promote the debate about pseudoscience and multiple forms of superstition so as to develop in our society a critical awareness of these forms of alienation and access to a scientifically based view on history of the mankind and of the universe.

Keywords: Alienation. Scientific education. Pseudoscience. Superstitions

Para citar - (ABNT NBR 6023:2018)

DUARTE, José B. Pauperização, consumismo, superstições e pedagogia social. Eccos - Revista Científica, São Paulo, n. 56, p. 1-13, e11504, jan./mar. 2021. Disponível em: https://doi.org/10.5585/eccos.n56.11504. 


\section{Pedagogia social de finalidade ética e cívica}

"We in a midst of Global Transformation, when a new progressive vision of the Good Society is struggling to take shape" (Guy Standing, 2013)

Um exemplo de otimismo face aos efeitos da globalização sobre a pobreza atual é a de Sachs (2005) pois que lembra que "a globalização, mais que qualquer outra coisa, reduziu o número de extrema pobreza em duzentos milhões de pessoas na Índia e de trezentos milhões de pessoas na China, desde 1990" (SACHS, 2005, p.355). Mas, por outro lado, o Forum de Davos, organização onde se reúnem dirigentes das maiores empresas do comércio global além dos políticos dos países mais poderosos, em 2014, reconheceu "a crescente distância entre ricos e pobres como o maior risco a enfrentar pela economia global na década seguinte" (BEDDOES, 2014, p.1), constatação reforçada, de acordo com os meios de comunicação social, no Forum de Davos de 2019, onde foi enfatizado que a riqueza tende a concentrar-se cada vez mais em menor número de pessoas. De sublinhar que Beddoes escreve numa publicação que se diz "liberal" advogando "livre mercado e sociedades abertas", mas já em 2014 constatava que a maioria da assistência de Davos concluiu que a "concentração da riqueza está a corroer a democracia”.

Os problemas trazidos pela atual economia globalizada levam a uma questão fundamental: o que pode a pedagogia social, nas instituições sociais e instituições escolares, fazer face à nova forma de capitalismo que a globalização está a impor à humanidade, capitalismo neoliberal de face oculta, oposto à regulação dos governos e dos sindicatos dos trabalhadores, baseado sobretudo na especulação financeira e que está a provocar crescente concentração da riqueza em cada vez menor número de pessoas e, logo, a "corroer a democracia"?

Numa análise relacionada com o crescente risco de pauperização que ameaça a população mundial, Standing, citado em epígrafe, traz ao debate, em várias obras (2011,2013), o aparecimento de um "precariado" (precariat) produzido pela globalização: uma classe emergente, caraterizada pela insegurança crónica, privada das tradicionais normas da classe trabalhadora, de que fazem parte jovens diplomados sem emprego, refugiados, trabalhadores moldados nos antigos modos industriais e inadaptados a uma tecnologia em mudança contínua. Neste contexto, enquanto anteriormente os partidos políticos, ao debaterem os problemas na perspetiva das classes que representavam, se aproximavam de uma democracia participativa, a globalização, em nítido contraste, está a produzir uma “democracia utilitarista" baseada na publicidade e consumo, enquanto os partidos maioritários 
fazem apelo ao voto por parte de uma maioria passiva e indefinida designada como "classe média".

Em suma, com a crescente distância entre ricos e pobres, o risco de precarização e pauperização paira sobre a humanidade. Algo confirmado pela Oxfam (organização de 20 instituições de diferentes países): "entre 2006 e 2015, os trabalhadores viram o seu rendimento crescer de $2 \%$ ao ano enquanto a riqueza dos multimilionários cresceu $13 \%(\ldots)$ pelo que $82 \%$ de toda riqueza global do último ano foi para uma elite de $1 \%$ e metade da população mundial não teve qualquer aumento" (OXFAM, 2018, p.10). Ora para Standing o precariado sofre de "défice deliberativo", mas como classe emergente pode tornar-se um "contra-movimento" que "lute por ocupar uma esfera pública onde a democracia deliberativa possa reviver" (STANDING, 2013, p.180). Para isso, pode usar os novos meios de comunicação social. E o autor sublinha que "o rendimento básico" pode dar uma ajuda "para essa intervenção".

Para Standing "filosoficamente, um rendimento básico pode ser pensado com um dividendo social" (STANDING, 2013, p.173) pois "qualquer pessoa rica em qualquer sociedade deve a sua riqueza aos esforços dos seus progenitores e aos esforços de outra gente menos rica". E sublinha que a segurança básica é instrumentalmente benéfica pois psicólogos como Evans e Schamberg (2009) concluem com as suas investigações que a insegurança produz ansiedade diminuidora das capacidades de trabalho e que, por outro lado, "as pessoas seguras são mais tolerantes e altruístas" (STANDING, 2013, p.175). E adverte com base nos mesmo autores: "que a insegurança socioeconómica tende a fazer fãs do neofascismo as pessoas que nos países ricos suportam descidas do seu nível de vida causadas pela globalização". Em suma, o rendimento básico pode ser uma contribuição fundamental para uma nova fase da humanidade.

Numa análise em boa parte precursora de Standing, Marcuse descreveu "um substrato de marginais, explorados e perseguidos de várias etnias, de desempregados e inempregáveis, debaixo de uma população básica conservadora" (MARCUSE, 1964, p.261), pois detentora de formas oficiais de democracia, mas comandada por um pensamento "unidimensional", forjado pelos interesses de mercado. Argumentou que essa "sociedade industrial avançada" criou "falsas necessidades" que submetem os indivíduos ao atual sistema de produção e de consumo, através de publicidade, gestão industrial e ideologia dominante. E, numa sugestão anunciadora de Standing, prevê que a aliança daquele substrato de desempregados e marginais 
com a "consciência mais avançada da humanidade" levará à "grande recusa" dessa visão conservadora e utilitarista.

Um pensador na linha de crítica ao consumismo é também Bauman: "é forte e generalizada a crença de que há um vínculo íntimo entre a felicidade e o volume e qualidade do consumo» (BAUMAN, 2009, p.28). Essa crença é ilusória pois « qualquer que seja a sua condição em matéria de dinheiro e crédito, você não vai encontrar num shopping o amor e a amizade, os prazeres da vida doméstica, a satisfação que vem de cuidar dos entes queridos ou de ajudar um vizinho em dificuldade, a auto-estima proveniente do trabalho bem-feito » (p.13). E reconhece que, numa sociedade que pretenda ser humanizada, dois valores devem prevalecer - a liberdade e a segurança social: "Se se considera o melhor na história do liberalismo e o melhor na história do socialismo, eles sempre convergem, há sempre essa conexão entre os dois " (BAUMAN, 2004,p.13). O autor associa a liberdade à vivência no ocidente capitalista mas reconhece que a segurança social é um princípio mais assegurado pelo socialismo. Por outras palavras e parafraseando Emmanuel Levinas, prossegue: "O meu socialismo, em meu entender, se resume na convicção de que, assim como o poder de carga de uma ponte se mede não pela força média de todos os pilares mas pela força de seu pilar mais fraco, a qualidade de uma sociedade também não se mede pelo PIB, pela renda média de sua população, mas pela qualidade de vida de seus membros mais fracos" (p.10).

Por isso Bauman faz apelo ao sentido ético da vida de cada ser humano: "todas as decisões que o ser humano toma em seu ambiente social (pois ninguém está sozinho, todos nós estamos conectados a outras pessoas) têm significado ético, têm um impacto em outras pessoas, mesmo quando só pensamos no que ganhamos ou perdemos com o que fazemos" (p.6). E aponta a responsabilidade de cada pessoa face à múltipla informação em que vivemos mergulhados na sociedade atual: "Dependemos todos uns dos outros e somos, num grau difícil de precisar, responsáveis pela situação dos demais; enfim, que o que se faz em uma parte do planeta tem um alcance global".

Ora os membros fracos da sociedade, em que se incluem aqueles que se situam no precariado, tendem a constituir a maioria da sociedade, pois envolvidos num contexto de automação e robotização em economia de mercado. Segundo a OCDE (2018), é sobretudo nas regiões com trabalho mais tradicionalista e menos remunerado, regiões onde a taxa de desemprego já é elevada, que a automação provoca mais desemprego. Por outro lado, a mesma instituição reconhece, se, com a automação, o desemprego tem sido mais duro nas profissões que comportam baixas qualificações, potencialmente as novas tecnologias tendem 
a trazer automatização futura às profissões altamente qualificadas. Por isso, Moutinho, avisa que o desemprego começa a ser verdade também para aqueles que "se julgavam fazer parte do clube dos donos, como os trabalhadores do setor financeiro (...) que tiveram a experiência provavelmente não compreendida do despedimento aos milhares durante a última crise do sistema" (MOUTINHO, 2011, p.236).

Em síntese, paira sobre a humanidade o problema do desemprego, com a crescente concentração da riqueza e com a inelutável expansão da inteligência artificial e da automação, cujos benefícios, por outro lado, são inegáveis em termos de facilitação de tarefas. Bauman, face à mutação permanente atual, avisa que a humanidade irá passar momentos difíceis nos tempos se aproximam, numa modernidade designada de "líquida" pelo autor: "Diferentemente da sociedade moderna anterior, que chamo de modernidade sólida (...) tudo está agora sendo permanentemente desmontado mas sem perspetiva de alguma permanência. Tudo é temporário" (BAUMAN, 2004, p.16).

Para Díaz "o indivíduo socializa-se dentro e fora da instituição escolar e, por isso, a educação social deve efetuar-se em todos os contextos nos quais se desenvolve a vida do ser humano" (DÍAZ, 2006, p.91). Pertinentemente para o autor caberá à pedagogia social a tarefa da reflexão teórica como disciplina científica enquanto descreve a educação social como espaço de intervenção prática. Concluamos que a pedagogia social, através da escola, da comunicação social e das diferentes organizações sociais (ligadas a autarquias, a associações populares ou outras) será fundamental para desenvolver a crítica sobre os "indiscutíveis" princípios do capitalismo neoliberal (justamente acusados de "pensamento único") e também a "recusa" às ilusões do consumo promovidas pela publicidade e pelas vaidades dos seres humanos,

Nessa perspetiva, a escola, os meios de comunicação social e as organizações sociais, como diferentes agências de pedagogia social, serão fundamentais para que, em cada jovem e em cada homem ou mulher, em termos de Gardner (2008), se desenvolva uma uma "mente disciplinada" com base numa formação académica, mas também uma «mente ética ». Mas que essa mente ética seja associada a uma "mente criadora", capaz de se abrir a novas ideias e a novos caminhos propiciados pelo domínio humanizado das tecnologias em constante renovação. Essa mente ética e criadora refletirá "sobre a natureza do trabalho de cada um e sobre os desejos e necessidades da sociedade em que vivemos" (GARDNER, 2008, p.13), para que os cidadãos possam "trabalhar altruisticamente de modo a melhorar o destino de todos". 
Em suma, à escola, aos meios de comunicação social e a outras agências de transformação social, cabe desenvolver uma pedagogia de finalidade ética e cívica, isto é, formar cidadãos autênticos empenhados numa sociedade mais justa e participada que saiba eleger e controlar/acompanhar "representantes políticos" respeitadores dos interesses da comunidade. Isto é, respeitadores e promotores dos interesses públicos e, logo, incorruptíveis (sem misturar os interesses do Estado com os interesses particulares e pessoais...).

Muitos pensadores têm, ao longo dos tempos, proposto que os setores fundamentais da economia sejam controlados pelo Estado para salvaguarda da soberania e melhor distribuição da riqueza. Mas temos visto como esses setores são muitas vezes inadequadamente geridos por gestores nomeados por critérios partidários. Para uma sociedade democrática participada são precisos outros dirigentes com verdadeira formação ética e cívica, além da competência e empenhamento. Compete a todas as instituições de pedagogia social, na educação formal e não-formal, promover essa formação. Mas tem faltado na educação social, na educação de adultos e mesmo na escola, a dimensão de uma formação científica, não apenas baseada em ciências sociais, mas aberta às ciências físico-naturais, como vamos argumentar.

\section{Educação científica versus pseudociência e superstições}

Como se disse, para além da pauperização e consumismo promovidas pelo capitalismo financeiro, outras formas de alienação tendem a manifestar-se na sociedade atual, assumidas por diferentes formas de pseudociência e superstição omnipresentes em todos os países, sob diferentes maneiras. Como exemplo da pseudociência, a maioria dos jornais diários, para além da informação geral, exibe dispendiosos anúncios por parte de diferentes "mestres" e videntes, que aliás são correntemente convidados para programas de tv e solicitados nas redes sociais da internet. Não esqueçamos, por outro lado, o espaço generoso que a maioria dos jornais concede aos signos do zodíaco ou previsões de idêntico teor, como se outros astros, além do Sol e da Lua, tivessem alguma influência na vida dos habitantes do nosso planeta. E nas ruas encontramos a todo o momento militantes de diferentes tipos de superstição à procura de aderentes. Em suma, como declara Allègre: "num mundo marcado pela racionalidade, a irracionalidade tende a tomar o poder, como o prova o desenvolvimento sem precedentes de astrólogos, cartomantes e seitas de toda a espécie" (ALLÈGRE, 2005, p.9)

Se precisamos de uma reflexão fundamental quanto às consequências sociais do mercado globalizado, precisamos, também, de opor-nos à pseudociência e às diferentes formas de superstição, que são, aliás, contexto fértil para aquela atmosfera de consumismo. 
Esta reflexão deve partir das escolas e da comunicação social de modo a influenciar as comunidades e instituições, pois as grandes arenas nacionais e internacionais são de mais difícil acesso mas podem ser influenciadas por mudanças nas instituições de menor dimensão. Sugestão que se depreende das propostas de Bauman e Gardner acima mencionadas sobre a participação de cada cidadão na melhoria de toda a humanidade.

As ciências sociais têm sido objeto de controvérsia amarga, de que o livro de Sokal e Bricmont (1998) foi um exemplo importante, ao fazer publicar numa revista sociológica um artigo construído ao "modo pós-modernista" que depois fez saber tratar-se de uma caricatura cheia de erros científicos disfarçados por linguagem atraente. Ora as ciências sociais deveriam cooperar com as ciências físicas na promoção de uma consciência crítica de base culturalcientífica, mas permitindo às ciências físico-naturais um papel fundamental na educação da sociedade ao lado da cultura humanística. O princípio fundamental a seguir é o de que a ciência é cultura e de que a cultura não é exclusiva das disciplinas "humanísticas" e de que, em suma, todas as disciplinas são válidas num dinâmico diálogo cultural e interdisciplinar.

Mas, para as áreas da educação social, mais marcadamente na educação de adultos, a finalidade central tem sido a da educação cívica ou, por vezes, a formação técnica e só implicitamente a educação científica. Na associação internacional ESREA (European Society for Research on the Education of Adults) as três primeiras linhas de pesquisa concretizadas em doze "networks" são “Access, Learning Careers and Identities”, “Active Democratic Citizenship and Adult Learning”, "Adult Educators, Trainers and their Professional Development" e as três últimas são "Migration, Transnationalism and Racisms", "Policy Studies in Adult Education”, “ Working Life and Learning”. Trata-se de importantes problemáticas da sociedade atual mas, tendo em conta a minha argumentação anterior acerca da pseudociência e superstições várias, faltará uma linha específica sobre educação científica.

No Brasil, segundo Saviani (2008), o conceito de Educação Popular, com base no pensamento de intelectuais esquerda e na doutrina social das igrejas, ganhou força a partir dos anos 80 com o sentido de crescente participação política das massas populares na vida cultural e política, dominada pelas elites. Nesse movimento importa salientar o conceito de "educação libertadora" de Freire no sentido de que "a educação não pode ser a do depósito de conteúdos mas a da problematização dos homens em suas relações com o mundo" (FREIRE, 1999, p.67). A força de toda a ampla bibliografia comentadora da obra de Freire vai no sentido da importância de uma educação cívica que possa fazer face a um mundo globalizado, 
numa dialética entre o local e o global, entre o cultural e o multicultural. Os casos exemplares de Torres sobre os dilemas da cidadania num mundo globalizado (2001) e de Gadoti (1999, 2000) que propõe uma escola cidadã e ecopedagógica, com retorno à comunidade e liberta de burocracias, baseada nas caraterísticas éticas e culturais de cada região. No caso português, Melo (2012), com base em Freire e nas propostas da Unesco, sintetiza assim uma necessária reorientação para a educação permanente abrangendo também a educação de adultos: "A Educação Permanente, tal como foi desenhada e teorizada nas décadas de 60 e 70, torna-se de novo fundamental para formar cidadãos mais informados, mais confiantes (...). As respostas às ameaças de opressão e dominação que hoje nos atingem terão de emergir de uma cidadania mais ativa e capaz de construir uma democracia de maior qualidade e uma economia ao serviço da vida" (MELO, 2012, p.517).

Em suma, as diferentes correntes da educação social têm tido uma orientação de formação cívica preponderante, ou por vezes formação técnica, em que a educação científica parece apenas implícita. Assim, à pedagogia social compete também uma discussão séria sobre o papel da educação científica na transformação do conhecimento popular. O debate sobre como as ciências físico-naturais podem ajudar os homens a entender a sua vida dentro de um mundo global e dentro do cosmos não é promovido devidamente pela comunicação social que depende muito da publicidade e das preferências do público leitor. Também não é adequadamente promovido nas escolas, orientadas por um currículo "prescrito" que tende a ser concretizado de forma verbalista, longe da narrativa pessoal e da criticidade, propostas por Goodson (2017) ou Apple e Beane (2007).

Ora na cultura comum, a ciência físico-natural deixou de ter o prestígio que teve no passado, em especial durante o século XIX e parte do século XX. Santos faz justamente notar que, por um lado, existe atualmente "a consciência de uma vital e crescente dependência" da ciência e tecnologia quanto ao "crescimento económico e da melhoria de aspetos cruciais da qualidade de vida" (SANTOS, 2017, p.69). Mas, por outro lado, sublinha "a perceção dos riscos tecnológicos e dos que resultam de uma progressiva artificialização e degradação do ambiente, associados àquela dependência". No final da obra, Santos mostra que depende de cada homem o enfrentamento desses riscos: "Todos nós temos oportunidades e possibilidades, embora diferenciadas, de contribuir para o desenvolvimento sustentável por meio de alteração de comportamentos, de ação cívica e do avanço e disseminação do conhecimento" (p.561). 


\section{A formação de uma cultura científica numa sociedade democrática global}

É de reconhecer que as ciências sociais desenvolveram interessantes teorias sobre as disparidades na sociedade atual e sobre o imperativo de extinguir essas disparidades. Mas lembro que o pensamento "mítico" ainda é omnipresente nas nossas sociedades, cuja imprensa diária está repleta de astrologia, enquanto múltiplas seitas espalham nos media e nas nossas ruas as suas práticas. Assim, parece pertinente compartilhar a proposta de Sagan $(2019,1995)$ que descreve a sedução da pseudociência na ausência da ciência: "A ciência desperta um sentimento sublime de admiração. Mas a pseudociência também produz esse efeito. As divulgações escassas e malfeitas da ciência abandonam nichos ecológicos que a pseudociência preenche com rapidez. Se houvesse ampla compreensão de que os dados do conhecimento requerem evidência adequada antes de poder ser aceitos, não haveria espaço para a pseudociência" (SAGAN, 2019, p.14). E Sagan aponta os meios de comunicação como corresponsáveis pela situação: “Com a cooperação desinformada (e frequentemente com a conivência cínica) dos jornais, revistas, editoras, rádio, televisão, produtoras de filmes e outros órgãos afins, essas ideias se tornam acessíveis em toda a parte. Muito mais difíceis de encontrar (...) são as descobertas alternativas, mais desafiadoras e até mais deslumbrantes da ciência” (p.22).

Lembro que a educação científica e a luta contra a pseudociência devem ser impulsionadas pela comunicação social mas começar na escola regular, incluindo os primeiros níveis de escolaridade, envolvendo toda a educação social, numa curiosidade epistémica sobre os problemas da nossa civilização e do universo. E Sagan sugere aos cientistas o modo de comunicar ciência: "Não falar para o público em geral como falaríamos com nossos colegas do ramo. Há termos que transmitem instantânea e acuradamente para os especialistas o que queremos dizer. (...) Mas elas não fazem mais do que mistificar um público de não-especialistas. Usar a linguagem mais simples possível. Acima de tudo, lembrar como é que pensávamos antes de compreender o que estamos explicando (SAGAN, 2019, p.284).

E Sagan, contrariando um atual funcionamento errado da comunicação social, como atrás citámos, sugere que "os periódicos e a televisão podem acender centelhas quando nos dão um vislumbre da ciência, o que é muito importante” (p.286). Mas o autor acrescenta que “à parte o aprendizado ou aulas e seminários bem estruturados, a melhor maneira de divulgar a ciência é por meio de livros didáticos, livros populares" e meios digitais. E Sagan justifica: "Pode-se ruminar a informação, seguir o próprio ritmo, rever as partes mais difíceis, comparar 
os textos, compreender em profundidade. Mas isso tem de ser feito de forma correta, e, sobretudo nas escolas, não é o que acontece”. Essa proposta de Sagan é também um desafio aos livros e outros didáticos que influenciam fortemente a orientação dos professores, mas que tendem atualmente a privilegiar um modelo meramente informativo em vez de um modo problematizador que desperte a curiosidade pelo saber (DUARTE, 2015).

Popper pronuncia-se também sobre o papel da educação científica numa democracia aberta. Para este autor, a tarefa mais importante para os cientistas é fazer um bom trabalho no seu campo específico, e uma segunda tarefa consiste em evitar uma especialização fechada. Mas o autor sublinha uma terceira tarefa, a de "falar simples e claramente sobre a ciência" com os outros cidadãos, de modo a contribuir para uma sociedade aberta e democrática" (POPPER, 1999, p.140).

Acender a "centelha" da inquietação pelos saberes, como sugere Sagan acima,, através de situações que despertem a curiosidade pela ciência, é um desafio a todas as agências de educação a começar pela escola. Arriscando controvérsias, sugiro algumas grandes desafios à nossa civilização a serem debatidos em todos os níveis da educação, nos diferentes meios de comunicação e organizações autárquicas ou associativas. Para o heliocentrismo, atomismo e outras teorias, a história da ciência pode ser altamente motivadora. Vejamos primeiramente o caso do primeiro conceito de átomo. Allègre descreve a reflexão de Demócrito na borda do Mar Egeu 400 anos a.C., ao observar que o vinho era secado ao Sol para ser depois transportado em pasta, que, após chegar ao destino, era dissolvida em água. Demócrito pensou que, para que isso acontecesse, a pasta teria de ser constituída "por partículas elementares, as quais, destacando-se da pasta, isolam-se umas das outras e penetram na água (...), ela também composta por partículas e vazio" (ALLÈGRE, 2005, p.15). A essas partículas, continua o autor, Demócrito chamou "átomos", ou seja, "constituintes elementares da matéria e indestrutíveis", um conceito que seria retomado e aprofundado ao longo da história.

Para o heliocentrismo, Popper descreve a persistência de Galileu a observar os satélites de Júpiter e a constatar que, com o decorrer das horas, esses pequenos astros se deslocavam em volta do astro maior. Galileu concluiu que esse seria também o caso da Terra em relação ao Sol. A propósito, Popper lembra a admiração de Galileu por Copérnico (seu contemporâneo) e Aristarco (sec. III a.C.), autores que antes dele defenderam o heliocentrismo, na obra "Diálogo sobre os Dois Grandes Sistemas do Mundo" em que Galileu confessa a sua admiração por esses sábios “em oposição feroz à prova dos seus próprios 
sentidos e por pura força do intelecto, preferirem o que lhes ditava a razão ao que a experiência dos sentidos lhes ditava" (POPPER, 1999, p.112)

E sugiro também o debate sobre astronomia/astrologia e conceções semelhantes, incluindo a fundamental importância do Sol para vida na Terra e o efeito da atração Terra/Lua nas marés (algo totalmente diferente da relação com outras estrelas ou planetas, como pretende a astrologia, pois que esses astros estão a uma longínqua distância).

E um debate geral deve ser incluído sobre questões adaptadas de Allègre, já citado (2005) acerca de novas formas de energia: aerogeradores e células fotovoltaicas (reduzindo as emissões de $\mathrm{CO}_{2}$ e ao mesmo tempo aumentando a nossa segurança energética); o hidrogénio como fonte de energia; a energia nuclear de $4^{\mathrm{a}}$ geração (consumindo cem vezes menos urânio e destruindo seus próprios resíduos). Por sua vez, Sagan sugere, entre outros temas, a apresentação sucessiva das maravilhas e os métodos da ciência pois "há um real drama humano no processo de descoberta" (SAGAN; 2019, p.322) e "os equívocos e erros fundamentais cometidos por cientistas famosos, líderes nacionais e figuras religiosas". Incluo também um problema polémico: OGM e bactérias transgénicas (como esperança de progressos na produção de alimentos para reduzir/parar fome em muitos países). E será de salientar as proposições de Sachs (2005), em termos socioeconómicos, sobre as responsabilidades das agências mundiais na erradicação da pobreza.

\section{Reflexão conclusiva}

Esses são alguns dos grandes temas científico-naturais para a educação social e educação de adultos. Mas uma alteração será também necessária nas escolas pois tendem a privilegiar o discurso do professor e não as dúvidas e perguntas dos jovens. A educação social e a educação permanente deveriam continuar a curiosidade pela ciência despertada nas escolas. Ora a educação de adultos e a educação social tendem a desenvolver uma formação cívica com base em disciplinas humanísticas ou uma educação técnica demasiado rápida para atestar competências profissionais, esperadas pelo mercado de trabalho. E as associações populares de cultura preferem promover artes (literatura, teatro, música) - o que é muito importante - mas promovem muito pouco o conhecimento das ciências físico-naturais.

Como um alarme, as escolas em geral estão a apresentar sinais claros de indisciplina pela tendência verbalista da função docente tradicional. A curiosidade pelas problemáticas da ciência é fundamental para motivar a aprendizagem e prevenir o tédio e a indisciplina nas nossas instituições educacionais e essa curiosidade pela ciência pode influenciar o modo de 
vida de toda a sociedade. Quanto à educação social, a curiosidade pelas diferentes ciências sociais e físico-naturais, a relacionar com importantes problemas económicos, sociais e ecológicos, contribuirá para uma nova consciência crítica da sociedade e um desejo de conhecer os segredos do universo e da vida.

\section{Referências}

ALLÈGRE, Claude. Um pouco de ciência para todos. Lisboa: Gradiva, 2005.

APPLE, Michael; BEANE, James. Democratic schools. 2nd edition. Portsmouth, NH: Heinemann, 2007.

BAUMAN, Zigmunt. A arte da vida. Rio: Zahar. 2009.

BAUMAN, Zigmunt. Entrevista com Pallares-Burke. Tempo.vol.16 no.1 São Paulo. 2004.

BEDDOES, Zanny. Inequality of plutocrats and progressivism. The Economist. Jan 27th 2014 https://www.economist.com/free-exchange/2014/01/27/of-plutocrats-andprogressivism?zid=309\&ah=80dcf288b8561b012f603b9fd9577f0e acesso em 2019.02.05

DÍAZ, Andrés. Uma aproximação à Pedagogia- Educação Social. Revista Lusófona de Educação, no7, p. 91-104. 2006.

DUARTE, J.B. Textbooks and curiosity for science. 12th Iartem Conference. Ostrava University. p. 216-228. 2015.

ESREA (European Society for Research on the Education of Adults). Networks. 2019 https://www.esrea.org/networks/ acesso 23.01.2019.

FREIRE, Paulo. Pedagogia do Oprimido. São Paulo: Edição Paz e Terra. 1999.

GADOTTI, Moacir. Escola cidadã. São Paulo: Cortez Editora. 1999.

GARDNER, Howard. Cinco mentes para o futuro. Lisboa: Actual Editora. 2008.

GOODSON, Ivor. Currículo, narrativa e o futuro social. Revista Brasilera de Educação v. 12 n. 35, pp.241-252. 2007.

MARCUSE, Herbert. (1964) One-dimensional man: studies in the ideology of advanced industrial society. London: Routledge. 1964.

MELO, Alberto. Passagens Revoltas. Lisboa: Associação in Loco.2012.

MOUTINHO, Mário. (2011). Pobres e ricos. A "Globalização Contemporânea" ultimo estádio do Capitalismo? Lisboa: Edições Colibri.2011. 
OCDE. Job creation and local economic development 2018: preparing for the future of work. OECD: Publishing Paris. 2018.

POPPER, Karl. O mito do contexto. Em defesa da ciência e da racionalidade. Lisboa: Edições 70. 1999.

SACHS, Jeffrey. The end of poverty. How we can make it happen in our lifetime. London. 2005.

SAGAN, Carl. O mundo assombrado pelos demônios. A ciência como uma vela no escuro. 1995.

https://edisciplinas.usp.br/pluginfile.php/567315/mod_resource/content/1/Carl\%20Sagan\%20 O\%20Mundo\%20Assombrado\%20Pelos\%20Demonios.pdf Acesso 2019.01.09.

SANTOS, Filipe. Que futuro? Ciência, tecnologia, desenvolvimento e ambiente. Lisboa: Gradiva. 2007.

SAVIANI, Dermeval. História das ideias pedagógicas no Brasil. Campinas: Autores Associados. 2008.

SOKAL, Alan.; BRICMONT, Jean. Intellectual Impostures. Postmodern Philosophers' abuse of Science. London: Profile Books. 1998.

STANDING, Guy. The Precariat: The New Dangerous Class. Londres: Bloomsberry. 2011.

STANDING, Guy. A Precariat Charter: From Denizens to Citizens. Londres: Bloomsberry. 2013.

TORRES, Carlos. Democracia, Educação e Multiculturalismo (Dilemas da Cidadania em um Mundo Globalizado). Petrópolis; Editora Vozes. 2001 